\title{
Release of Mast Cell Tryptase into Saliva: A Tool to Diagnose Food Allergy by a Mucosal Challenge Test?
}

\author{
Franziska Ruëffa $^{a}$ Tanja Friedl $^{a} \quad$ Alexander Arnold $^{a}$ Matthias Kramer ${ }^{b}$ \\ Bernhard Przybilla ${ }^{a}$ \\ ${ }^{a}$ Klinik und Poliklinik für Dermatologie und Allergologie und ${ }^{b}$ Klinik und Poliklinik für Hals-Nasen-Ohrenheilkunde, \\ Ludwig-Maximilians-Universität, München, Deutschland
}

\section{Key Words}

Challenge test $\cdot$ Diagnostic tests $\cdot$ Food allergy .

Oral allergy syndrome $\cdot$ Tryptase

\begin{abstract}
Background: Our aim was to examine whether measurement of the saliva mast cell tryptase (MCT) concentrations before and after a mucosal challenge test with the offending food would be helpful in diagnosing food allergy. Methods: We performed a retrospective analysis of 44 food challenge tests performed in 38 patients between 2006 and 2009. Patients with a suspected history of food allergy chewed the food until they developed symptoms or until the amount of time known from the patients' history to usually be required for the provocation of symptoms had passed. In 5 patients, saliva samples for the measurement of MCT were collected at minutes $0,1,4,8,11$, and 16 after the first onset of symptoms. The remainder of the patients only had samples taken before chewing and $4 \mathrm{~min}$ after the end of the test period. Results: During repeated measurements, MCT peaked about $4 \mathrm{~min}$ after the onset of symptoms $(p=0.028)$. During 33 of the 44 tests $(75.0 \%)$, we observed oral symptoms during testing; after 25 of the 33 (75.8\%) tests evoking symptoms, the saliva MCT concentration increased. The MCT increase was negative in all other tests where no oral symptoms could be provoked. Conclusions: The measurement of saliva MCT
\end{abstract}

4 min after the onset of symptoms may be helpful to diagnose food allergy. Because of numerous confounding variables, however, a negative saliva MCT increase does not exclude food allergy.

Copyright $\odot 2011$ S. Karger AG, Basel

\section{Introduction}

Systemic allergic reactions or local oral symptoms (oral allergy syndrome; OAS) are manifestations of food allergy. Characteristic symptoms of OAS are itching and/ or swelling of the oropharyngeal mucosa immediately after contact with food allergens. In many cases, these unpleasant symptoms prevent the patient from further consuming the food allergen. This type of behavior limits the individual's allergen exposure and may explain why many patients have only oral, but no systemic symptoms to food allergens. Another reason for the low incidence of systemic reactions in patients with OAS might result from the instability of some food allergens, which are degraded rapidly by oxidation or by digestive secretions. However, some patients with OAS may develop

Franziska Ruëff and Tanja Friedl equally contributed to the manuscript.

\section{KARGER}

Fax +41613061234 E-Mail karger@karger.ch www.karger.com
(C) 2011 S. Karger AG, Basel

$1018-2438 / 11 / 1553-0282 \$ 38.00 / 0$

Accessible online at:

www.karger.com/iaa
Correspondence to: PD Dr. Franziska Ruëff

Klinik und Poliklinik für Dermatologie und Allergologie

Ludwig-Maximilians-Universität, Frauenlobstrasse 9-11

DE-80337 Munich (Germany), Tel. +49 895160 6170, Fax +49 8951606162

E-Mail Franziska.Rueff@med.uni-muenchen.de 
systemic symptoms up to the point of anaphylactic shock [1-3].

In patients with systemic allergic reactions after food exposure, a double-blind placebo-controlled food challenge (DBPCFC), which includes swallowing the culprit food, is the diagnostic procedure of choice. The standard procedure to diagnose OAS is mainly based on a history of typical local symptoms shortly after exposure to certain foods. Results of skin prick tests and/or of measurements of specific serum IgE antibodies may be also helpful but are affected by a comparably low accuracy. The use of mucosal challenge tests is limited because they require specific local symptoms which, however, are rarely unequivocal. To date, an objective parameter to verify oral symptoms is not available.

An increase in the mast cell tryptase (MCT) concentration in bodily fluids is a diagnostic correlate of mast cell-related events and was found for the first time in the serum of patients with anaphylactic reactions $[4,5]$. After a local allergen challenge, MCT concentrations also rise in nasal secretions [6-8], tears [9], bronchoalveolar lavage fluid [10], and sputum [7].

A preliminary study in patients with food allergy suggested that measurement of the saliva MCT concentrations before and after an oral food challenge may not be a suitable tool to document local reactivity [11]. The experimental design of the latter study, however, may have been inadequate. Since 2006, we have been using a modified routine procedure for oral food challenges and the measurement of saliva MCT concentrations. These differences mainly concern the food exposure time and the time when MCT is measured after the challenge. Before establishing a fixed time point for MCT measurement, we examined the postchallenge kinetics of saliva MCT in patients with OAS. We performed mucosal food challenges in patients with a history of OAS, but also in patients who exclusively developed systemic allergic reactions after food ingestion. In the latter patients, we also tried to avoid DBPCFC and the risk of a subsequent severe anaphylactic reaction. In the present communication, we report our preliminary experience with this modified challenge procedure in diagnosing food allergy.

\section{Methods}

\section{Subjects}

We conducted a retrospective search for all patients who had presented with a history of food allergy in our outpatient clinic and who had undergone a routine food challenge test including postchallenge saliva MCT measurements between 2006 and 2009.
Patients who had received antihistamines or other drugs with an antihistamine-like action (e.g. antidepressants) were not considered for the evaluation. Patients who had not been sensitized to the suspected food were also excluded from the evaluation.

The retrospective analysis of anonymous data was approved by the local institutional review board.

\section{Basic Allergy Diagnostics}

The patients' history included atopic diseases, the type of symptoms induced by foods, offending foods, the perceived eliciting dose of the respective food, the time interval between food intake and the onset of systemic or local symptoms, and medications used. Skin prick tests were performed using a standard series (ALK-Abelló, Hørsholm, Denmark; Allergopharma Joachim Ganzer KG, Reinbek, Germany; Bencard Allergie $\mathrm{GmbH}, \mathrm{Mu}-$ nich, Germany; HAL Allergy, Leiden, The Netherlands, or Stallergenes, Antony Cedex, France) which included the suspected foods. If there was no prick test reaction to a commercial test solution of the suspected food, fresh foods were used. A positive skin prick test was defined as a wheal of $\geq 3 \mathrm{~mm}$ in diameter. Physiologic saline served as a negative control, and histamine dihydrochloride $(10 \mathrm{mg} / \mathrm{ml})$ served as a positive control. Specific serum IgE antibodies to the suspected food were measured by ImmunoCAP (Phadia, Freiburg, Germany).

Mucosal Challenge Test and Measurement of MCT in Saliva

The tests were performed with fresh foods, which were potential candidates for an allergic reaction according to history and test results. The routine test procedures were standardized. Before testing, written consent was obtained from all patients or legal guardians. The average amount of test food corresponded to that consumed by a usual bite - about 3-10 g. Patients took this amount of food into their mouth and started to chew in the customary manner until they developed symptoms or until the amount of time had passed which was known from the same patients' history to usually be required for the provocation of oral symptoms. Patients without a history of oral reactions also started to chew until they developed symptoms or until the amount of time which was known from other patients' history to usually be required for the provocation of symptoms had passed. If the food had already been thoroughly chewed before the end of this time span was reached, the patient spat out the previous test dose and took another equal dose of fresh food into his or her mouth. The patients were advised to avoid any swallowing of the food.

If symptoms of any kind occurred during the test period, the test was considered clinically positive and was immediately stopped by properly spitting out the food, if necessary, several times. Patients were not allowed to rinse their mouth or to brush their teeth after the end of the test. The test was considered clinically negative if no symptoms occurred until the end of the test period. Saliva samples were obtained using the cotton wool method [12] as follows: Small absorbent cotton wool dental rolls (Celluron Zahnwatterollen; Hartmann, Heidenheim, Germany) with a length of about $4 \mathrm{~cm}$ and a diameter of about $6 \mathrm{~mm}$ were placed under the tongue. Each sampling period lasted $1 \mathrm{~min}$. After their removal, the dental rolls were centrifuged $(3,000 \mathrm{rpm}, 10 \mathrm{~min}$, $4^{\circ} \mathrm{C}$ ), and the supernatants were analyzed for MCT by ImmunoCAP (Phadia). The detection limit of MCT was $1 \mu \mathrm{g} / \mathrm{l}$. An increase in saliva MCT from baseline of more than $20 \%$ was defined as a positive test result. 
In the first 5 patients with a high likelihood of suffering from OAS (6 challenge tests), saliva samples were collected at various points in time, i.e. before ( $0 \mathrm{~min})$, immediately $(1 \mathrm{~min})$, and 4,8 , 11 , and 16 min after the onset of symptoms. In subsequent patients, saliva MCT was only measured before the test and 4 min after the first symptoms had occurred. In case of a negative clinical result, corresponding measurements were taken 4 min after the end of the test period. In a few selected patients with a positive clinical response and a saliva MCT increase, placebo challenges (chewing gum) were done to exclude unspecific effects.

\section{Control Challenge Tests in Healthy Volunteers}

Three healthy controls ( 1 male, 30 years old, and 2 females, 30 and 51 years old, respectively) were studied to exclude an unspecific oral MCT release by the act of mastication. The subjects chewed up to $90 \mathrm{~g}$ of carrots for $3 \mathrm{~min}$. Controls were matched according to age and food exposure time. A 3-min test time was used in controls because this was the average amount of exposure time, which was known from the patient's history to usually be required for the provocation of symptoms. The type of food was not matched with the food tested in the patients. Instead, we wanted to test in controls the type of food which would lead to the greatest physical strain during the act of mastication.

\section{Statistics}

Data were analyzed using software (SPSS 15.0; SPSS, Inc., Chicago, Ill., USA). Values are given as medians and ranges or means. Wilcoxon's test was used to compare different means of saliva MCT levels. $\chi^{2}$ tests were used to compare categorical variables. $\mathrm{p}<0.05$ was considered statistically significant.

\section{Results}

\section{Clinical Observations}

Altogether, 38 patients ( 9 males and 29 females, median age 34.5 years, range 10-71) with a history of food allergy and sensitization to the suspected food, in whom we had performed mucosal tests with 44 foods, were identified. Thirty-three of these patients had a history of atopic diseases [allergic rhinoconjunctivitis $(\mathrm{n}=31)$; asthma $(\mathrm{n}=10)$, and atopic eczema $(\mathrm{n}=6)]$. Thirty-one patients had a history of OAS; another 7 patients were tested to diagnose a food allergy with a history of an exclusively systemic allergic response after food intake.

During 44 challenges 33 oral reactions (75.0\%) occurred, none of which was associated with a subsequent systemic allergic reaction. Oral symptoms cleared within 2-15 min after the end of the test. Mild symptoms faded sooner than more intensive symptoms. Details are given in table 1. On average, the median exposure time to the development of clinical symptoms during a challenge test was $135 \mathrm{~s}$ (range 40-510). The median amount of chewed food was $11.7 \mathrm{~g}$ (range $0.02-79$ ). In 11 challenge tests, we could not provoke oral allergic reactions. For those tests,

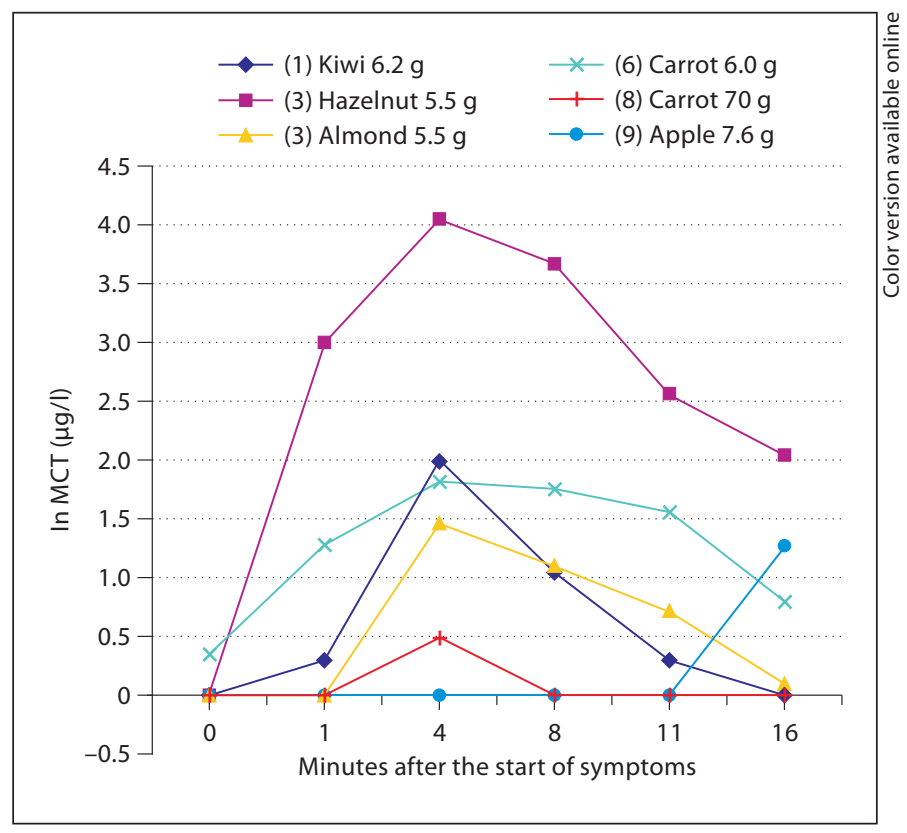

Fig. 1. Kinetics of the saliva MCT concentration after food exposure. Six tests were performed in 5 patients with a high likelihood of suffering from an OAS. Saliva samples were collected before (0 min), immediately ( $1 \mathrm{~min}$ ), and 4, 8, 11, and 16 min after the onset of oral symptoms. Patient numbers are given in parentheses.

the median exposure time was $1 \mathrm{~min}$ (range 1-10), and the median amount of food chewed was $22.3 \mathrm{~g}$ (range 5.7164.3). After one of the challenge tests, during which we did not observe an oral reaction, a systemic reaction occurred after the end of the test. This patient was a 35 -yearold male with a suspected sesame allergy. Upon mucosal challenge with $11.6 \mathrm{~g}$ sesame, he suffered from urticaria, dizziness, and dyspnoea $15 \mathrm{~min}$ after the test. Placebo challenges in 3 patients and dummy challenges in 3 control subjects were not associated with any oral reactions.

\section{Kinetics of MCT Release into Saliva}

Six kinetic analyses were performed in 5 subjects. Repeated measurements were performed with 1 food in 4 patients and with 2 different foods in 1 patient (patient No. 3). In the majority of the tests, saliva MCT concentrations were already increased 4 min after the appearance of the first symptoms. However, the time of the maximum concentration was not uniform. In patient No. 9 (test with $7.6 \mathrm{~g}$ apple) the saliva MCT concentration rose for the first time only 16 min after the beginning of the symptoms (fig. 1). This patient was challenged a second time with an artificially higher dose of apple (48.3 g), 
Table 1. Patient and test characteristics (patients No. 3, 15, and 23 were tested twice with different foods)

\begin{tabular}{|c|c|c|c|c|c|c|c|}
\hline $\begin{array}{l}\text { Patient } \\
\text { No. }\end{array}$ & $\begin{array}{l}\text { Age } \\
\text { years }\end{array}$ & Sex & Tested food & $\begin{array}{l}\text { Types of previous } \\
\text { symptoms }\end{array}$ & $\begin{array}{l}\text { Food-specific IgE } \\
\text { concentration, } \mathrm{kU} / \mathrm{l}\end{array}$ & $\begin{array}{l}\text { Prick test reaction } \\
\text { to tested food }\end{array}$ & $\begin{array}{l}\text { History of } \\
\text { atopic diseases }\end{array}$ \\
\hline 1 & 36 & $\mathrm{~F}$ & kiwi & OAS & 1.64 & yes & no \\
\hline 2 & 54 & $\mathrm{~F}$ & almond & OAS, AX III & 9.79 & yes & RCA \\
\hline $3 a$ & 21 & $\mathrm{~F}$ & hazelnut & OAS & 3.65 & yes & $\mathrm{A}, \mathrm{RCA}$ \\
\hline $3 b$ & & & almond & OAS & $<0.35$ & yes & \\
\hline 4 & 20 & $\mathrm{~F}$ & peach & OAS & 0.47 & yes & $\mathrm{AE}$ \\
\hline 5 & 29 & $\mathrm{M}$ & hazelnut & OAS & 1.48 & yes & RCA \\
\hline 6 & 35 & $\mathrm{~F}$ & carrot & OAS & 3.78 & n.d. & RCA \\
\hline 7 & 60 & $\mathrm{~F}$ & soy drink & OAS & $<0.35$ & yes & A, RCA \\
\hline 8 & 24 & $\mathrm{~F}$ & carrot & OAS & 3.47 & yes & A, RCA \\
\hline 9 & 21 & $\mathrm{~F}$ & apple & OAS & 5.56 & n.d. & RCA \\
\hline 10 & 29 & M & apple & OAS & 1.96 & yes & RCA \\
\hline 11 & 25 & $\mathrm{~F}$ & salmon & AX II & $<0.35$ & yes & no \\
\hline 12 & 55 & $\mathrm{~F}$ & apple & OAS & $<0.35$ & yes & RCA \\
\hline 13 & 41 & $\mathrm{M}$ & carrot & OAS, AX I & 6.16 & yes & A \\
\hline 14 & 28 & $\mathrm{~F}$ & celery & AX III & 0.35 & yes & RCA \\
\hline $15 \mathrm{a}$ & 46 & $\mathrm{~F}$ & cape gooseberry & OAS, AX II & n.d. & yes & $\mathrm{RCA}, \mathrm{AE}$ \\
\hline $15 b$ & & & peach & OAS, AX II & 3.89 & yes & \\
\hline 16 & 23 & $\mathrm{~F}$ & soy drink & OAS; AX III & 0.48 & yes & RCA \\
\hline 17 & 34 & $\mathrm{~F}$ & hazelnut & OAS & 3.37 & n.d. & RCA \\
\hline 18 & 35 & $\mathrm{~F}$ & hazelnut & OAS & 13.7 & n.d. & RCA \\
\hline 19 & 60 & $\mathrm{~F}$ & hazelnut & OAS & 0.82 & yes & A, RCA \\
\hline 20 & 64 & $\mathrm{~F}$ & sesame & OAS, AX II & 12.7 & yes & $\mathrm{RCA}$ \\
\hline 21 & 22 & $\mathrm{~F}$ & soy drink & OAS, AX II & 9.64 & yes & $\mathrm{RCA}, \mathrm{AE}$ \\
\hline 22 & 63 & $\mathrm{~F}$ & macadamia nut & OAS, AX II & $<0.35$ & yes & $\mathrm{A}, \mathrm{RCA}$ \\
\hline $23 a$ & 59 & $\mathrm{~F}$ & hazelnut & AX I & $>100$ & yes & A, RCA \\
\hline $23 b$ & & & almond & AX I & $<0.35$ & yes & \\
\hline 24 & 13 & $\mathrm{M}$ & kiwi & AX I & $<0.35$ & yes & A, RCA \\
\hline 25 & 21 & $\mathrm{M}$ & walnut & AX IV & 33.9 & yes & RCA \\
\hline 26 & 49 & $\mathrm{~F}$ & hazelnut & OAS & 6.04 & yes & RCA \\
\hline 27 & 67 & $\mathrm{~F}$ & kiwi & OAS & $<0.35$ & yes & no \\
\hline 28 & 55 & $\mathrm{~F}$ & soy drink & OAS, AX II & 17.1 & yes & RCA, A \\
\hline 29 & 71 & $\mathrm{M}$ & kiwi & OAS & 0.47 & yes & RCA \\
\hline 30 & 36 & $\mathrm{~F}$ & celery & OAS & 20.6 & yes & RCA \\
\hline
\end{tabular}

Only those patients who developed oral symptoms upon mucosal food challenge are presented. $\mathrm{F}=\mathrm{Female} ; \mathrm{M}=\mathrm{male}$; $\mathrm{n}$. $\mathrm{d}$. $=$ not done; $\mathrm{AE}=$ atopic eczema; $\mathrm{A}=$ asthma; $\mathrm{RCA}$ = allergic rhinoconjunctivitis; $\mathrm{AX}=$ systemic anaphylactic reactions; $\mathrm{I}=$ mild reactions limited to the skin (e.g. angioedema, flush, and urticaria); II = moderate gastrointestinal, cardiovascular, and/or pulmonary symptoms (e.g. nausea, dyspnea, and dizziness); III = severe cardiovascular, and/or pulmonary symptoms (e.g. loss of consciousness, and asthma); IV $=$ arrest.

causing an accelerated MCT release already detectable 4 min after the onset of symptoms. On average, the maximum MCT during follow-up were significantly higher than the basal values (mean $13.1 \pm 21.4 \mu \mathrm{g} / \mathrm{l}$, median 5.2 $\mu \mathrm{g} / \mathrm{l}$, range 1.64-56.6, vs. mean $0.24 \pm 0.58 \mu \mathrm{g} / \mathrm{l}$, median $0 \mu \mathrm{g} / \mathrm{l}$, range $<1.0-1.42 ; \mathrm{p}=0.028)$.

\section{Postchallenge Saliva MCT Concentration}

On the basis of the results of the kinetic analyses, and for the sake of simplicity, we decided to subsequently measure saliva MCT concentrations only 4 min after the beginning of the symptoms or after the end of the test period. In 3 of the 30 patients with oral symptoms and in 1 of 8 patients without symptoms at the challenge test, MCT was demonstrable in saliva at baseline (table 2). Altogether, in 23 patients, food challenge caused an elevation in saliva MCT 4 min after the beginning of the first symptoms in 25 tests versus baseline (median $2.7 \mu \mathrm{g} / \mathrm{l}$, range $0-79.4$, mean $9.1 \pm 17.1 \mu \mathrm{g} / \mathrm{l}$, vs. median 0 , range $0-2.6$, mean $0.2 \pm 0.6 \mu \mathrm{g} / \mathrm{l} ; \mathrm{p}=0.001$ ) (table 2). The sa- 
Table 2. Procedure and results of mucosal challenge tests (patients No. 3, 15, and 23 were tested twice with different foods)

\begin{tabular}{|c|c|c|c|c|c|c|}
\hline $\begin{array}{l}\text { Patient } \\
\text { No. }\end{array}$ & Food challenge & $\begin{array}{l}\text { Amount of food } \\
\text { which caused } \\
\text { symptoms, g }\end{array}$ & $\begin{array}{l}\text { Duration of mucosal } \\
\text { challenge until devel- } \\
\text { opment of symptoms }\end{array}$ & $\begin{array}{l}\text { Severity } \\
\text { of } \\
\text { symptoms }\end{array}$ & $\begin{array}{l}\text { Baseline saliva } \\
\text { MCT concen- } \\
\text { tration, } \mu \mathrm{g} / \mathrm{l}\end{array}$ & $\begin{array}{l}\text { Saliva MCT concen- } \\
\text { tration } 4 \text { min after } \\
\text { start of symptoms, } \mu \mathrm{g} / \mathrm{l}\end{array}$ \\
\hline 1 & kiwi & 6.2 & 120 & moderate & 0 & 7.31 \\
\hline 2 & almond & 10.0 & 120 & mild & 1.45 & 9.06 \\
\hline $3 a$ & hazelnut & 5.5 & 40 & moderate & 0 & 56.6 \\
\hline $3 b$ & almond & 5.5 & 40 & moderate & 0 & 4.29 \\
\hline 4 & peach & 10.7 & 60 & mild & 0 & 0 \\
\hline 5 & hazelnut & 5.5 & 60 & severe & 0 & 0 \\
\hline 6 & carrot & 6.0 & 100 & moderate & 1.42 & 6.16 \\
\hline 7 & soy drink & 15.0 & 60 & mild & 0 & 0 \\
\hline 8 & carrot & 70.0 & 270 & mild & 0 & 1.64 \\
\hline 9 & apple & 48.3 & 120 & moderate & 0 & 2.51 \\
\hline 10 & apple & 79.0 & 145 & mild & 0 & 1.5 \\
\hline 11 & salmon, uncooked & 25 & 161 & mild & 2.61 & 15.8 \\
\hline 12 & apple & 35.8 & 240 & mild & 0 & 2.66 \\
\hline 13 & carrot & 41 & 160 & severe & 0 & 79.4 \\
\hline 14 & celery & 15.2 & 140 & severe & 0 & 3.69 \\
\hline $15 \mathrm{a}$ & peach & 74 & 510 & moderate & 0 & 3.03 \\
\hline $15 b$ & cape gooseberry & 16.1 & 340 & mild & 0 & 0 \\
\hline 16 & soy drink & 10 & 90 & moderate & 0 & 8.74 \\
\hline 17 & hazelnut & 7.7 & 120 & severe & 0 & 8.91 \\
\hline 18 & hazelnut & 7.4 & 105 & moderate & 0 & 1.42 \\
\hline 19 & hazelnut & 5.9 & 180 & severe & 0 & 0 \\
\hline 20 & sesame & 0.02 & 100 & mild & 0 & 2.57 \\
\hline 21 & soy drink & 40 & 240 & mild & 0 & 0 \\
\hline 22 & macadamia nuts & 11.7 & 170 & moderate & 0 & 1.13 \\
\hline $23 \mathrm{a}$ & hazelnut & 0.54 & 120 & mild & 0 & 2.99 \\
\hline $23 b$ & almond & 0.49 & 120 & mild & 0 & 2.8 \\
\hline 24 & kiwi & 23.8 & 170 & mild & 0 & 0 \\
\hline 25 & walnut & 0.36 & 120 & moderate & 0 & 0 \\
\hline 26 & hazelnut & 3.0 & 135 & moderate & 0 & 18.8 \\
\hline 27 & kiwi & 53 & 240 & moderate & 0 & 13.7 \\
\hline 28 & soy drink & 20.0 & 150 & mild & 0 & 1.74 \\
\hline 29 & kiwi & 44.6 & 180 & moderate & 0 & 5.47 \\
\hline 30 & celery & 32.6 & 240 & moderate & 0 & 36.9 \\
\hline
\end{tabular}

Only those patients who developed oral symptoms upon mucosal food challenge are presented.

liva MCT increase was positive in 25 of 33 of the tests (75.8\%) which had revealed oral symptoms during food exposure. None of the patients in whom oral reactions were absent during the challenge demonstrated an MCT increase in saliva at the 4-min measurement. The one patient who developed an exclusive systemic reaction after the challenge did not reveal an MCT increase in saliva either.

We also compared patients with a history of OAS to those who had had systemic allergic symptoms after food exposure. The percentage of patients who had a positive MCT increase after a positive clinical reaction upon food challenge was comparable ( $80.0 \%$ in 5 patients with a history of an exclusively systemic reaction and $72.0 \%$ in 25 patients with a history of OAS; n.s.).

Three selected patients in whom saliva MCT concentrations rose after the food challenge (No. 8, 17, and 18) underwent a placebo challenge with chewing gum. These patients neither developed symptoms nor showed changes in the saliva MCT concentration. In 3 healthy subjects, no symptoms occurred when chewing carrot for $3 \mathrm{~min}$. In these subjects, MCT in the saliva was not measurable before or after the mucosal challenge test. 


\section{Discussion}

In our institution, measurement of saliva MCT was incorporated into routine food challenge tests in 2006. Because the postchallenge kinetics of saliva MCT concentrations were largely unknown, we first tried to find out, using repeated measurements in patients with a high likelihood of oral symptoms, whether there was a preferred time point for a single posttest measurement.

In the majority of patients who had repeated measurements during a 16 -min postchallenge time, the maximum saliva MCT concentration occurred 4 min after the beginning of symptoms. Individual patients were tested with different foods and reacted in a similar way. In one patient who had initially had a delayed increase in MCT in saliva, we found that an artificially higher food dose increased the saliva MCT concentration already at $4 \mathrm{~min}$. According to the results from placebo tests in patients and dummy tests in healthy controls, we can exclude an unspecific saliva MCT release by the act of mastication.

During repeated measurements, the most striking observation was the rapid, but temporary increase in saliva MCT, which started to decline again after a few minutes. In the majority of patients, saliva MCT started to rise within $1 \mathrm{~min}$ after the appearance of the first subjective oral symptoms and returned to the pretest values after 16 min or more. According to the results of repeated measurements, however, it must be noted that there may be individual patients with a markedly delayed MCT response. In those patients, an MCT increase would be missed by the 4-min measurement.

Further prospective studies will be required to precisely describe the time course of the saliva MCT concentration after a challenge and to define optimal time points for sampling and the number of samples. It may be advisable to modify the challenge protocol in a way that the dose of test food is increased above the amount which has been indicated before by the patient to have resulted in symptoms. Increasing the number of early sampling points will be limited by restrictions concerning the sublingual application time of the cotton roll. A time of less than 1 min will not be long enough to allow the cotton roll to absorb amounts of saliva, which are currently sufficient for a precise MCT measurement.

The postchallenge kinetics of MCT release into saliva appear to differ from what had been observed in other bodily fluids after allergen exposure. After a local allergen challenge, a significant increase in MCT was demonstrable in tear fluid only after $20 \mathrm{~min}[9,13]$, and in nasal secretions only after $30 \mathrm{~min}$ [7]. Although MCT has a half-life of several hours, it is measurable only during a short period of time because saliva is swallowed and because tears and nasal secretions are removed quickly. The rapid disappearance of MCT from saliva suggests that mucosal MCT release stops rapidly after the end of allergen exposure. However, we cannot exclude the possibility that there might be a late phase reaction in single patients or a biphasic course of mucosal MCT release.

Using the 4-min postchallenge sampling point, we subsequently incorporated measurement of saliva MCT into routine mucosal challenge tests performed to diagnose patients with food allergy. A posttest increase in saliva MCT could be found in the vast majority of tests (79\%), which was associated with oral symptoms upon food challenge. If a patient had not developed oral symptoms during the challenge ( $25 \%$ of the tests), there was no change in the saliva MCT concentration. Moreover, the percentage of positive MCT responses did not depend on whether the tests had been performed in patients who had presented with a history of oral symptoms or in those with a history of exclusively systemic symptoms. In the latter patients, we could avoid DBPCFC in 4 out of 5 cases by already obtaining a positive test result after the mucosal challenge.

The finding of a negative MCT increase in combination with a negative clinical result after the mucosal food challenge is difficult to interpret. Besides limitations due to the MCT saliva sampling point (see above), other explanations are possible such as: (a) a change in the individual pattern of immunological reactions by a variety of patient-specific mechanisms, (b) a change in food allergenicity for a variety of reasons (food generation, storage), and (c) an insufficient duration of oral food exposure. Therefore, the lack of a MCT release in the presence or absence of oral symptoms cannot be taken as a finding allowing the exclusion of a food allergy. On the other hand, a positive saliva MCT increase in combination with clinical symptoms should - when compared to the presence of subjective clinical symptoms alone - significantly facilitate the diagnosis of a food allergy.

Our results are seemingly in contradiction to results reported by Vila et al. [11]. These authors reported an increased saliva MCT concentration in only 1 out of 8 patients, all of whom had a systemic allergic reaction to a food challenge test. Their test design differed fundamentally from that of our test in that the oral exposure time was not determined by the time which was known from the patient's history to usually be required for the provocation of oral symptoms. Patients were only asked to swallow the food after it had been chewed sufficiently, and there was no intention of making the patient keep the 
food in his or her mouth beyond this point (until oral symptoms appeared). Another difference was that saliva MCT was only measured 5, 30, and 60 min after swallowing the last test dose, and the collection time was not related to the onset of oral symptoms.

There are two mechanisms which possibly explain the negative results obtained by Vila et al. [11]. According to our results, the time which had passed between oral exposure and MCT measurement may have been too long to still allow the detection of MCT in saliva. Furthermore, there may be some type of mast cell exhaustion becoming evident after repeated exposure to the same type of food during a comparatively short time period. Finally, it should be noted that the molecular weight of MCT is of such a magnitude that the transport of MCT from serum into saliva is not possible; this principally prevents the detection of a primary systemic allergic reaction via saliva examinations [14].

Our study has several limitations mainly concerning the execution of the challenge test. The principal aim of our challenge procedure was to provoke clinical symptoms irrespective of the dose of food. Patients chewed the food to be examined until they developed symptoms or until that amount of time had passed, which was known from their history to usually be required for the provocation of symptoms. Because the provocation time varied from patient to patient and between different types of food (depending on consistency), the amount of food actually chewed during the test also varied significantly. Because the history of the patient was a central part of the individual planning and execution of the test, a certain subjective component remains. Nevertheless, even when considering those limitations, definitive conclusions can be made if positive MCT test results are obtained. The comparably high percentage of positive MCT results in patients with oral symptoms during testing suggests that - in the context of our study design - measurement of allergen-induced saliva MCT may be a promising novel diagnostic tool to confirm food allergy in patients with OAS and possibly also with anaphylaxis. In the latter patients, the need for a DBPCFC may even be eliminated.

\section{Acknowledgement}

The authors thank W. Hartl, MD, for the critical revision of the manuscript.

\section{References}

1 Rodriguez J, Crespo JF, Burks W, Rivas-Plata C, Fernandez-Anaya S, Vives R, Daroca P: Randomized, double-blind, crossover challenge study in 53 subjects reporting adverse reactions to melon (Cucumis melo). J Allergy Clin Immunol 2000;106:968-972.

2 Kleine-Tebbe J, Vogel L, Crowell DN, Haustein UF, Vieths S: Severe oral allergy syndrome and anaphylactic reactions caused by a Bet $\mathrm{v}$ 1-related PR-10 protein in soybean, SAM22. J Allergy Clin Immunol 2002;110: 797-804.

3 Alemán A, Sastre J, Quirce S, de las Heras M, Carnés J, Fernández-Caldas E, Pastor C, Blázquez AB, Vivanco F, Cuesta-Herranz J: Allergy to kiwi: a double-blind, placebocontrolled food challenge study in patients from a birch-free area. J Allergy Clin Immunol 2004;113:543-550.

4 Schwartz LB, Metcalfe DD, Miller JS, Earl H, Sullivan T: Tryptase levels as an indicator of mast-cell activation in systemic anaphylaxis and mastocytosis. N Engl J Med 1987;316: 1622-1626.

5 Schwartz LB, Bradford TB, Rouse C, Irani A-M, Rasp G, van der Zwan JK, Van der Linden PW: Development of a new, more sensitive immunoassay for human tryptase: use in systemic anaphylaxis. J Clin Immunol 1994; 14:190-204

6 Svensson C, Grönneberg R, Andersson M, Alkner U, Andersson O, Billing B, Gilljam H,
Greiff L, Persson CG: Allergen challenge-induced entry of alpha 2-macroglobulin and tryptase into human nasal and bronchial airways. J Allergy Clin Immunol 1995;96:239246.

7 Marcucci F, Sensi L, Di Cara G, Salvatori S, Bernini M, Pecora S, Burastero SE: Threeyear follow-up of clinical and inflammation parameters in children monosensitized to mites undergoing sub-lingual immunotherapy. Pediatr Allergy Immunol 2005; 16:519526.

8 Niedoszytko M, Chełmińska M, Chełmiński K, Knopińska-Posłuszny W, GruchałaNiedoszytko M, Jassem E: Late-phase allergic reaction in nasal provocation with fungal allergens. Allergy Asthma Proc 2008;29:35-39.

9 Margrini L, Bonini S, Centofanti M, Schiavone $\mathrm{M}$, Bonini S: Tear tryptase levels and allergic conjunctivitis. Allergy 1996;51:577581.

10 Ali FR, Kay AB, Larché M: Airway hyperresponsiveness and bronchial mucosal inflammation in $\mathrm{T}$ cell peptide-induced asthmatic reactions in atopic subjects. Thorax 2007;62: 750-757.

11 Vila L, Sanz ML, Sánchez-López G, GarcíaAvilés C, Diéguez I: Variations of serum eosinophil cationic protein and tryptase, measured in serum and saliva, during the course of immediate allergic reactions to foods. Allergy 2001;56:568-572.
12 Kramer MF, Burow G, Pfrogner E, Rasp G: In vitro diagnosis of chronic nasal inflammation. Clin Exp Allergy. 2004;34:1086-1092.

13 Bacon AS, Ahluwalia P, Irani AM, Schwartz LB, Holgate ST, Church MK, McGill JI: Tear and conjunctival changes during the allergen-induced early- and late-phase responses. J Allergy Clin Immunol 2000;106:948-954.

14 Sommerhoff CP, Bode W, Matschiner G, Bergner A, Fritz H: The human mast cell tryptase tetramer: a fascinating riddle solved by structure. Biochim Biophys Acta 2000; 1477:75-89.

15 Ballmer-Weber BK, Holzhauser T, Scibilia J, Mittag D, Zisa G, Ortolani C, Oesterballe M, Poulsen LK, Vieths S, Bindslev-Jensen C: Clinical characteristics of soybean allergy in Europe: a double-blind, placebo-controlled food challenge study. J Allergy Clin Immunol 2007;119:1489-1496.

16 Gubesch M, Theler B, Dutta M, Baumer B, Mathis A, Holzhauser T, Vieths S, BallmerWeber BK: Strategy for allergenicity assessment of 'natural novel foods': clinical and molecular investigation of exotic vegetables (water spinach, hyacinth bean and Ethiopian eggplant). Allergy 2007;62:1243-1250.

17 Mari A, Ballmer-Weber BK, Vieths S: The oral allergy syndrome: improved diagnostic and treatment methods. Curr Opin Allergy Clin Immunol 2005;5:267-273. 